\section{Cureus}

Received 01/04/2018

Review began 01/08/2018

Review ended 01/12/2018

Published 01/20/2018

\section{(c) Copyright 2018}

$\mathrm{Ng}$ et al. This is an open access article distributed under the terms of the Creative Commons Attribution License CC-BY 3.0., which permits unrestricted use, distribution, and reproduction in any medium, provided the original author and source are credited.

\title{
Conservative Management of Acalculous Cholecystitis in a Seven-year-old Child
}

\author{
Jessica Y. $\mathrm{Ng}^{1}$, Jennie $\mathrm{Gu}^{1}$ \\ 1. Surgery, Gold Coast University Hospital
}

$\square$ Corresponding author: Jessica Y. Ng, jessica.ng@health.qld.gov.au

Disclosures can be found in Additional Information at the end of the article

\section{Abstract}

Acute acalculous cholecystitis is an uncommon disease in children and is usually associated with trauma, burns, and infections. Whereas acute acalculous cholecystitis is only seen in $10 \%$ of cholecystitis in adults, it is uncommon in the paediatric population.

A seven-year-old male presented to the emergency department of a regional hospital with a 36hour history of right-upper-quadrant abdominal pain. He had associated symptoms of anorexia, nausea, and vomiting. He was septic with raised white cell count and inflammatory markers. Diffuse gallbladder wall thickening without intraluminal sludge or calculi was seen on abdominal ultrasound. He was found to have a concurrent right-upper lobe pneumonia on further investigation. The patient was treated with antibiotics and responded well to supportive and conservative management with close radiological monitoring.

Acute acalculous cholecystitis is associated with a high mortality rate (30\%) and significant complications such as gangrene, empyema, and perforation in $40 \%$ of adult cases. Acute surgical management has been traditionally advocated, however, surgery is not without risks; studies have suggested that non-operative intervention may be appropriate for selected critically ill children with an underlying cause.

Herein, we discuss the safe and effective conservative treatment of acute acalculous cholecystitis in lieu of operative management and highlight the importance of recognising this disease in paediatric patients with acute abdominal pain and coexisting infection.

Categories: Pediatric Surgery, General Surgery

Keywords: acalculous cholecystitis, paediatric, surgery

\section{Introduction}

Calculous cholecystitis is a rare disease in children, with 1.3 paediatric cases for every 1000 adult cases [1]. Acalculous cholecystitis (AC) is even more uncommon, comprising only $50 \%$ of these paediatric cholecystitis cases [2]. This condition is associated with bacterial (Salmonella, Brucella, Campylobacter, Leptospira), fungal (Candida), viral (Hepatitis A and B, Epstein-Barr virus, Cytomegalovirus) and parasitic infections (Giardiasis, Malaria, Echinococcus, Ascaris Lumbricoides) [3-7]. It is related to trauma, burns, postoperative patients, and total parenteral nutrition [3,8-10]. Cases have been described in autoimmune conditions such as Kawasaki's disease, Periarteritis nodosa and Systemic Lupus Erythematosus [10]. It can also occur in otherwise healthy children. 


\section{Cureus}

\section{Case Presentation}

A seven-year-old, Caucasian boy was bought into the Emergency Department with 36-hour history of right-sided abdominal pain associated with nausea, anorexia, and vomiting. He reported no coryzal symptoms or changes in bowel motions and medical history was unremarkable. He had no perinatal or developmental issues and all immunisations were up to date.

On examination, the child looked well, was warm and well perfused. He was not tachypnoeic and was saturating at $98 \%$ on room air. He was febrile to 39 degrees on arrival, with a heart rate of 130. Chest sounds were equal and bilaterally vesicular and abdomen was soft but distended. He had generalised tenderness, worst in the right upper and lower quadrants. Bowel sounds were present and external genitalia were unremarkable.

A urine microscopy was unremarkable. Initial blood showed a haemoglobin of $109 \mathrm{~g} / \mathrm{L}$, white cell count of $15.5 \times 10^{\wedge} 9 / \mathrm{L}$, platelets of $203 \times 10^{\wedge} 9 / \mathrm{L}$ and C reactive protein of $301 \mathrm{mg} / \mathrm{L}$. His albumin was $25 \mathrm{~g} / \mathrm{L}$ (range 32-47), total bilirubin was $20 \mathrm{umol} / \mathrm{L}$ (range <20) and conjugated bilirubin was 6 umol/L (range <4). His electrolytes, other liver function tests (LFTs) and lipase were unremarkable. An abdominal ultrasound showed a mildly enlarged, heterogenous liver with no focal abnormality. Diffuse gallbladder wall thickening up to $4.6 \mathrm{~mm}$ with pericholecystic collection was identified - no intraluminal sludge or calculi seen (Figure 1). The common bile duct measured $2 \mathrm{~mm}$. A chest X-ray revealed a large focal area of consolidation seen in the right upper mid zone, consistent with right-upper lobe pneumonia. Cardiac and mediastinal silhouette were within normal limits (Figure 2).

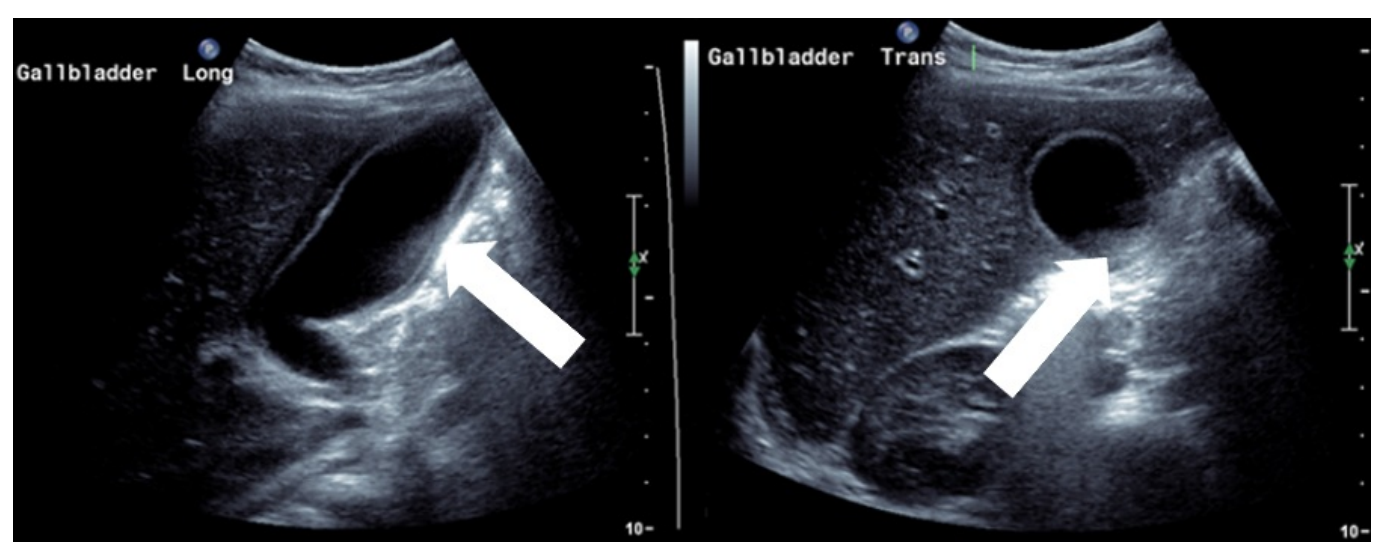

FIGURE 1: Ultrasound gallbladder - diffuse gallbladder wall thickening with pericholecystic collection. No intraluminal sludge or calculi seen. 


\section{Cureus}

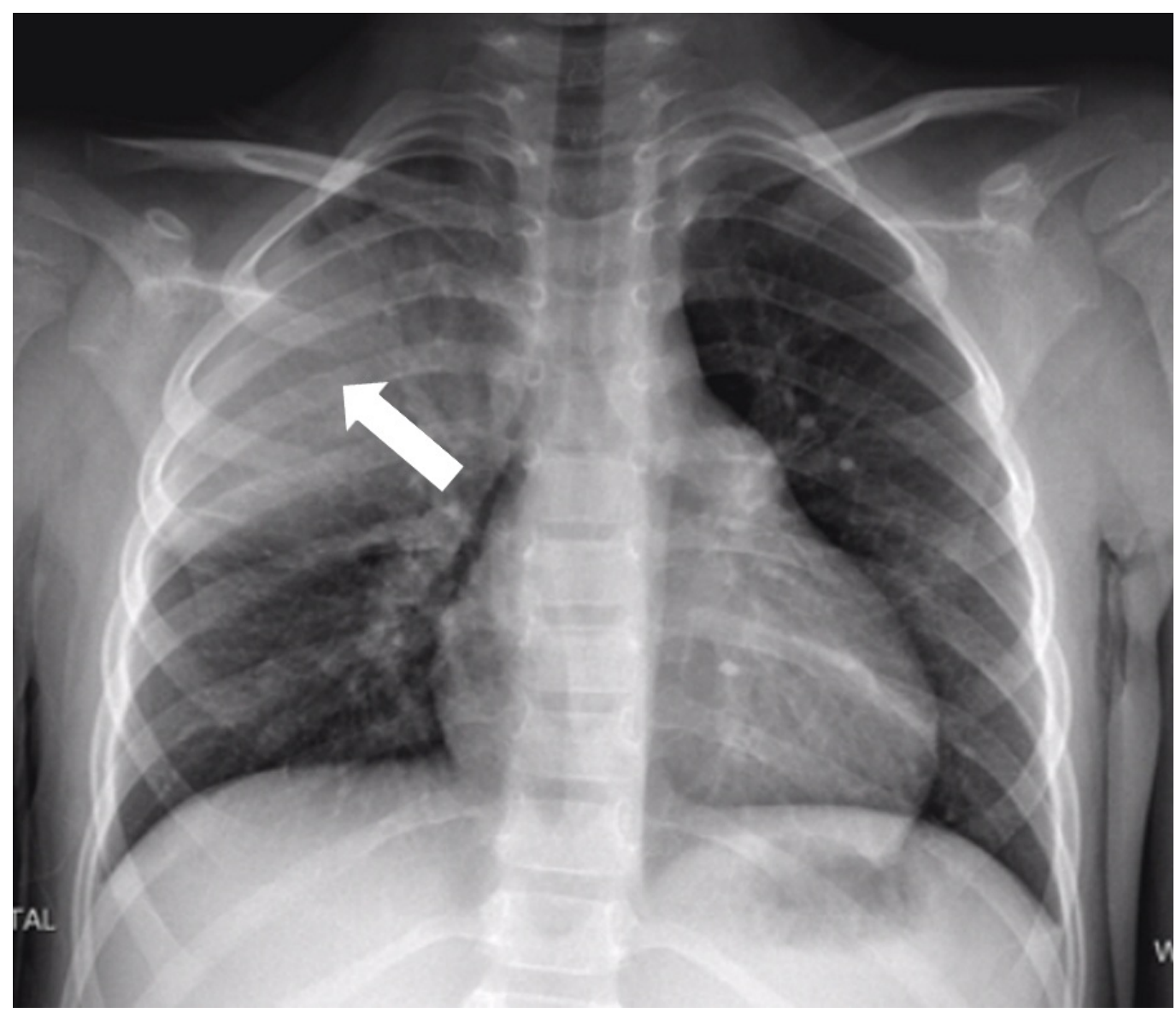

FIGURE 2: Chest X-ray - large focal area of consolidation seen in the right upper mid zone, consistent with right-upper lobe pneumonia.

The patient was initiated on ceftriaxone and metronidazole. Bilirubin normalised and LFTs remained normal during admission. Blood cultures were negative. Symptoms improved over the next few days and a repeat ultrasound showed resolution of cholecystitis. After five-day of IV antibiotics, he was discharged home with a five-day course of amoxycillin and clavulanic acid.

He was readmitted two days later with worsening respiratory symptoms and ongoing fevers due to worsening pneumonia and development of a right-sided multi-loculated pleural effusion (Figure 3). Video-assisted thoracoscopic surgery and breakdown of locules were performed and an intercostal catheter was inserted. He was treated empirically with IV lincomycin and cefotaxime until sensitivities of pleural cultures were revealed a Staphylococcus warneri which was sensitive to flucloxacillin. His blood anti-streptolysin O titre was $1150 \mathrm{U} / \mathrm{mL}$ (range <200). Serial abdominal ultrasound scan revealed no recurrence of his cholecystitis. He was discharged on oral amoxicillin after a four-day admission and was reviewed in outpatient department three weeks later with complete resolution of all symptoms. 


\section{Cureus}

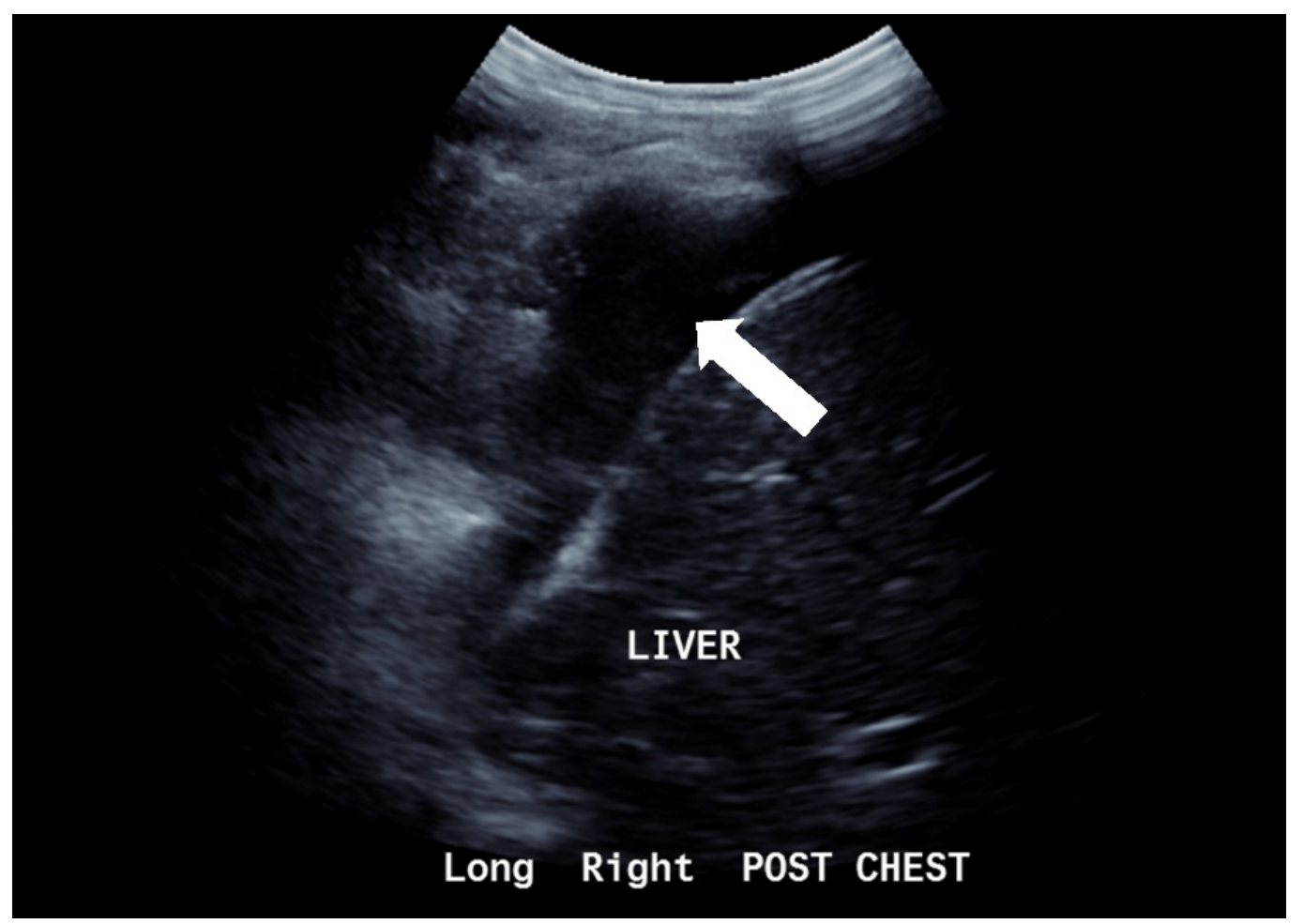

FIGURE 3: Ultrasound chest - complex septated right-sided effusion with associated low level internal echoes.

\section{Discussion}

Acute acalculous cholecystitis (AAC) is associated with a high mortality (30\%), with complications of gangrene, empyema, and perforation occurring in $40 \%$ of adult cases [2,3]. Hence acute surgical management has been traditionally advocated.

Diagnosis is complicated by these other underlying diseases, and hence is often delayed. The exact cause remains unclear. Ultrasonography is the diagnostic imaging procedure of choice, as it is portable, noninvasive, relatively inexpensive, and bears no radiation risk to the paediatric patient [8].

Therapeutic options advocated for AAC include cholecystectomy or cholecystostomy [3]; traditionally cholecystectomy is the procedure of choice. Tsakayannis et al., in their series of 12 patients, treated the majority of patients with cholecystectomy [9]. They suggested nonoperative intervention may be appropriate for selected critically ill children with an underlying cause, i.e., infection. In a similar study of 12 patients by Imamoglu et al., they advocated initial non-operative treatment with serial ultrasound scan to determine the most favourable time for operative intervention [8].

Other studies showed management with appropriate antibiotics and supportive therapy to be adequate. Thambidorai et al. studied the outcomes of nonsurgical management of AAC in a series of 14 cases associated with enteric fever [7]. All patients recovered uneventfully without the need for surgery [7]. Gora-Gebka et al. described two cases of AAC secondary to viral illness (Epstein-Barr virus and cytomegalovirus) which were successfully treated conservatively [5].

\section{Conclusions}


In conclusion, AAC needs to be considered as a differential in all children who present with acute abdominal pain, particularly in the setting of other infective illness, trauma or surgery. Conservative, supportive management and treatment of the underlying condition may be safe and effective in lieu of operative management.

\section{Additional Information \\ Disclosures}

Human subjects: Consent was obtained by all participants in this study. Conflicts of interest: In compliance with the ICMJE uniform disclosure form, all authors declare the following:

Payment/services info: All authors have declared that no financial support was received from any organization for the submitted work. Financial relationships: All authors have declared that they have no financial relationships at present or within the previous three years with any organizations that might have an interest in the submitted work. Other relationships: All authors have declared that there are no other relationships or activities that could appear to have influenced the submitted work.

\section{References}

1. Hawkins PE, Graham FB, Holliday P: Gallbladder disease in children . Am J Surg. 1996, 111:741-744. 10.1016/0002-9610(66)90054-7

2. Huffman JL, Schenker S: Acute acalculous cholecystitis: a review . Clin Gastroenterol Hepatol. 2010, 8:15-22. 10.1016/j.cgh.2009.08.034

3. Barie PS, Eachempati SR: Acute acalculous cholecystitis. Gastroenterol Clin N Am. 2010, 39:343-357. 10.1016/j.gtc.2010.02.012

4. Abdur-Rahman OL, Adeniran OJ, Nasir AA: Outcome of acalculous cholecystitis from typhoid in Nigerian children. J Nati Med Assoc. 2009, 101:717-719. 10.1016/S0027-9684(15)30982-2

5. Gora-Gebka M, Liberek A, Bako W, et al.: Acute acalculous cholecystitis of viral aetiology - a rare condition in children?. J Pediatr Surg. 2008, 43:25-27. 10.1016/j.jpedsurg.2007.10.073

6. Saha A, Batra P, Vilhekar KY, et al.: Acute acalculous cholecystitis in a child with Plasmodium falciparum malaria. Ann Trop Paediatr. 2005, 25:141-142. 10.1179/146532805X45755

7. Thambidorai CR, Shyamala J, Sarala R, et al.: Acute acalculous cholecystitis associated with enteric fever in children. Pediatr Infect Dis J. 1995, 14:812-813.

8. Imamoglu M, Sarihan H, Sari A, et al.: Acute acalculous cholecystitis in children: diagnosis and treatment. J Pediatr Surg. 2002, 37:36-39. 10.1053/jpsu.2002.29423

9. Tsakayannis DE, Kozakewich HPW, Lillehei CW: Acalculous cholecystitis in children. J Pediatr Surg. 1996, 31:127-131. 10.1016/S0022-3468(96)90334-6

10. Ternberg JL, Keating JP: Acute acalculous cholecystitis, complication of other illnesses in childhood. Arch Surg. 1975, 110:543-547. 10.1001/archsurg.1975.01360110089016 